\title{
Impact of electric field on Hofmeister effects in aggregation of negatively charged colloidal minerals
}

\author{
YING TANG ${ }^{\mathrm{a}, \mathrm{b}}$, HANG LI $^{\mathrm{a}, *}$, HUALING ZHU ${ }^{\mathrm{a}, *}$, RUI TIAN ${ }^{\mathrm{a}}$ and XIAODAN GAO ${ }^{\mathrm{a}}$ \\ ${ }^{a}$ Chongqing Key Laboratory of Soil Multi-Scale Interfacial Process, College of Resources and Environment, \\ Southwest University, Chongqing 400715, China \\ ${ }^{\mathrm{b}}$ Research Center for Eco-Environmental Sciences, Chinese Academy of Sciences, Beijing 100085, China \\ e-mail: lihangswu@163.com; zhhl000@126.com
}

MS received 3 September 2015; revised 23 October 2015; accepted 9 November 2015

\begin{abstract}
In this study, the aggregation kinetics of negatively charged colloidal minerals in $\mathrm{Na}^{+}, \mathrm{K}^{+}, \mathrm{NH}_{4}^{+}$, $\mathrm{Mg}^{2+}, \mathrm{Ca}^{2+}$ and $\mathrm{Cu}^{2+}$ solutions were measured and Hofmeister effects therein were estimated through total average aggregation (TAA) rates and critical coagulation concentration (CCC). Hofmeister effects of TAA rates increased exponentially with the increase in electric field strength, which cannot be explained by the classical theories (i.e., ionic size, hydration and dispersion forces), indicating strong electric field at colloidal surface was an indispensable factor in studying Hofmeister effects. Meanwhile, Hofmeister series of CCC values $\mathrm{Na}^{+}>\mathrm{K}^{+}>\mathrm{NH}_{4}^{+}>\mathrm{Mg}^{2+}>\mathrm{Ca}^{2+}>\mathrm{Cu}^{2+}$ show fine correlation with the polarization of various cations, implying that onic polarization in strong electric field would be responsible for Hofmeister effects in aggregation of colloidal minerals, and the deduction was confirmed by the calculated results of electrostatic interactions between colloidal minerals.
\end{abstract}

Keywords. Electric field; Hofmeister effects; ionic polarization; colloidal minerals; electrostatic interaction.

\section{Introduction}

Aggregation and dissociation of colloidal and mineral particles is a corner stone issue in a variety of disciplines. ${ }^{1,2}$ According to the Derjaguin, Landau, Verwey and Overbeek (DLVO) theory, the aggregation processes of the charged colloidal particles are determined by the competition between long-range van der Waals force and electrostatic repulsion force, where the electrostatic repulsion force is dominated by the electrostatic field strength in the diffuse layer. The magnitude of the electric field strength in the diffuse layer are influenced by valence and concentration of the adsorbed counter-ions, ions with equal valence and concentration which would therefore exhibit identical capacity in precipitating charged colloidal minerals; this is in contradiction with our experimental observations that diverse aggregation kinetics were detected for different cation species. These phenomena are called Hofmeister effects which have been rarely investigated in aggregation of multi-component colloidal particles.

Hofmeister effects or specific ion effects refer to the relative effectiveness of cations or anions to exhibit various specificities on a host of phenomena. ${ }^{3}$ Following pioneering experiments conducted on the capacity of

\footnotetext{
*For correspondence
}

ions to stabilize protein solutions against precipitation by Franz Hofmeister in the late $19^{\text {th }}$ century, it was clear that aggregation and sedimentation of proteins in electrolyte solutions vary remarkably with ionic species, even if the valence and chemical nature of these ions are similar. ${ }^{4}$ Over the last decades, Hofmeister effects have been observed ubiquitously in colloidal, nanocrystal and biological systems, including bacteria growth, ${ }^{5,6}$ enzyme activity, ${ }^{7-9}$ colloidal stability, ${ }^{3,10}$ cation exchange equilibrium ${ }^{11}$ and mineral dissolution. ${ }^{12}$ These effects can influence the interactions of ions with different interfaces (metal/water, air/water, oil/water and water/solid), ${ }^{13,14}$ as well as affect the physicochemical properties of the solution or colloids, such as activity coefficient, Zeta potential, freezing point, osmotic pressure, photoluminescence and catalytic properties. ${ }^{14-20}$

The widespread applicability of Hofmeister effects in different fields and their unclear origin make the clarification of the underlying mechanism one of the tremendous challenges in interfacial and colloidal science. Many efforts have been made to uncover the origin of Hofmeister effects. Generally, Hofmeister effects were observed at relatively high ionic concentrations $(>100 \mathrm{mmol} / \mathrm{L})$, where the long-range electrostatic interactions are screened, the hydration ${ }^{12,21,22}$ and dispersion effects ${ }^{23-27}$ become significant and are 
employed to interpret Hofmeister effects. However, further studies indicated that Hofmeister effects are also present at low electrolyte concentration $(<100$ $\mathrm{mmol} / \mathrm{L}$ or even lower). ${ }^{3,14,28-32}$ In addition, Hofmeister effects are found to be more pronounced at very dilute concentration, ${ }^{11,31,33,34}$ but classical theories including hydration effects, ionic size and dispersion force could not give a reasonable interpretation to this phenomenon. ${ }^{34}$ Fortunately, several recent studies ${ }^{33-35}$ have disclosed the essential role of polarization effect played in Hofmeister effects at interface surfaces, and these results provided motivation for us.

Furthermore, some investigations ${ }^{8,29,32}$ along with the present work pointed out that quite a different Hofmeister series were observed at relatively low and high ionic concentration. Usually, the reversal or partial alteration of Hofmeister series are relevant to change of the nature of the particle surface, including the cationic or anionic character ${ }^{3,28,36,37}$ and the hydrophobic/hydrophilic character of the particle surface. ${ }^{3,28,38}$ However, few studies considered the influence of surface charges on the Hofmeister effects and series, although considerable charges exist in the proximity of nano and colloidal particles surface (e.g., membrane, natural clay, metal oxides, protein, and soil colloidal particles), ${ }^{39-42}$ which can influence the quantity of adsorbed counter-ions and their distributions in the diffuse layer, and ultimately influence the interactions between these particles. Therefore, the present work aims to reveal Hofmeister effects on aggregation processes of negatively charged colloidal minerals at relatively low ionic concentrations and clarify the underlying impact of electric field around particle surface on Hofmeister effects. The aggregation kinetics were measured in the presence of various nitrate solutions $\left(\mathrm{NaNO}_{3}, \mathrm{KNO}_{3}, \mathrm{NH}_{4} \mathrm{NO}_{3}, \mathrm{Ca}\left(\mathrm{NO}_{3}\right)_{2}, \mathrm{Mg}\left(\mathrm{NO}_{3}\right)_{2}\right.$ and $\left.\mathrm{Cu}\left(\mathrm{NO}_{3}\right)_{2}\right)$ with different concentrations by the dynamic light scattering method. We found that pronounced Hofmeister effects were exhibited in colloidal mineral particles aggregation at dilute cationic concentration $(<100 \mathrm{mmol} / \mathrm{L})$ and electric field surrounding particle surface profoundly affected Hofmeister effects in aggregation of colloidal minerals.

\section{Experimental and computational}

\subsection{Preparation of colloidal minerals}

Colloidal minerals in the $<300 \mathrm{~nm}$ size fraction were extracted from a permanently charged purple soil according to the following procedure. Firstly, $50.0 \mathrm{~g}$ airdried samples $(<0.25 \mathrm{~mm})$ in $500 \mathrm{~mL}$ of ultrapure water were treated with $10 \mathrm{mmol} / \mathrm{L} \mathrm{KOH}$ solution to adjust the $\mathrm{pH}$ to 7.5. The suspension was then ultrasonicated at a frequency of $20 \mathrm{kHz}$ using a probe-type ultrasonic homogenizer (Scientz-IID, Ningbo Scientz Biotechnology Co., Ltd., Zhejiang, China) before diluting to $5000 \mathrm{~mL}$ with ultrapure water. Finally, colloidal minerals in suspension were extracted and collected by sedimentation according to Stokes' Law. ${ }^{43}$ The density of the suspension was approximately $0.672 \mathrm{~g} / \mathrm{L}$, as determined by the oven drying method. Note that the concentration of $\mathrm{K}^{+}$in the bulk suspension was less than $10^{-5} \mathrm{~mol} / \mathrm{L}$ as measured with a flame photometer, thus can be neglected. The quantitative analyses of the X-ray diffraction pattern of the colloidal minerals indicated that Vermiculite (33.6\%), montmorillonite $(23.5 \%)$ and illite $(15.3 \%)$ were the dominant components. The specific surface area $\left(421 \mathrm{~m}^{2} / \mathrm{g}\right)$, surface charge number $(-104 \mathrm{cmol} / \mathrm{kg})$ and electric field strength $(-3.41 \times$ $10^{8} \mathrm{~V} / \mathrm{m}$ ) at surface of the colloidal minerals were measured by a combined determination method ${ }^{39}$ at neutral $\mathrm{pH}$. The high negative surface charges of the colloidal minerals implied the overall hydrophilicity for the colloidal minerals surface, irrespective of the siloxanes (Si-O-Si) are hydrophobic and detected in several clay minerals, such as montmorillonite. ${ }^{44}$

\subsection{The dynamic light scattering measurement}

A BI-200SM multi-angle laser light scattering instrument (Brookhaven Instruments Corporation, New York, USA) with an autocorrelator of BI-9000AT was used to measure the variation of the scattering light intensity and effective hydrodynamic diameter of aggregates during the aggregation process. The power of the laser device is $15 \mathrm{~mW}$ and was vertically polarized with a wavelength of $532 \mathrm{~nm}$. The slit was set to $100 \mathrm{~nm}$ and the scattering angle was set to $90^{\circ}$. The dynamic light scattering experiments were performed to measure the aggregation kinetics of colloidal minerals in blank solution (i.e., without electrolytes) and then in diverse nitrate solutions with various concentrations. The optimized particle density in suspension was adjusted to $0.0420 \mathrm{~g} / \mathrm{L}$ for the subsequent experiments. Electrolyte concentrations were set as 20,30,50,60,80, 100 and $120 \mathrm{mmol} / \mathrm{L}$ for $\mathrm{NaNO}_{3} ; 10,15,20,30,50,80,100$ and $120 \mathrm{mmol} / \mathrm{L}$ for $\mathrm{NH}_{4} \mathrm{NO}_{3}$ and $\mathrm{KNO}_{3} ; 0.5,1,2,3,5,10$, 20 and $30 \mathrm{mmol} / \mathrm{L}$ for $\mathrm{Ca}\left(\mathrm{NO}_{3}\right)_{2} ; 0.5,1,1.5,2,3,5,10$ and $20 \mathrm{mmol} / \mathrm{L}$ for $\mathrm{Mg}\left(\mathrm{NO}_{3}\right)_{2} ; 0.1,0.5,1,3,5,8$ and $10 \mathrm{mmol} / \mathrm{L}$ for $\mathrm{Cu}\left(\mathrm{NO}_{3}\right)_{2}$. Experimentally, the suspensions containing a given quantity of colloidal minerals were subjected to sonication for a $5 \mathrm{~min}$ period before adding to the $\mathrm{NH}_{4} \mathrm{NO}_{3}, \mathrm{NaNO}_{3}, \mathrm{KNO}_{3}, \mathrm{Mg}\left(\mathrm{NO}_{3}\right)_{2}$, $\mathrm{Ca}\left(\mathrm{NO}_{3}\right)_{2}$ and $\mathrm{Cu}\left(\mathrm{NO}_{3}\right)_{2}$ solutions within various concentrations. After the formation of a uniform mixture at 
$298 \mathrm{~K}$ in a screw-capped glass vial, the corresponding data of effective hydrodynamic diameter of aggregates as well as scattering light intensity was automatically recorded for every 30 seconds with the dynamic light scattering instrument.

\subsection{Calculation of interaction forces}

2.3a The surface potential and electric field strength: The surface potential $\varphi_{0}(\mathrm{~V})$ of the negatively charged colloidal minerals in 1:1 or 2:1 electrolyte solution for various concentrations can be respectively calculated by Eqs. (1) and (2). ${ }^{39}$

1:1 electrolyte solution:

$$
\varphi_{0}=-\frac{2 R T}{\beta Z F} \ln \left[2 \frac{a^{0}}{\tilde{c}}\right]
$$

2:1 electrolyte solution:

$$
\varphi_{0}=-\frac{2 R T}{\beta Z F} \ln \left[\sqrt{3} \frac{a^{0}}{\tilde{c}}\right]
$$

where $R\left(\mathrm{~J} \mathrm{~K}^{-1} \mathrm{~mol}^{-1}\right)$ is the universal gas constant, $T(\mathrm{~K})$ is the absolute temperature, $F(\mathrm{C} / \mathrm{mol})$ is Faraday constant, $Z$ is the charge of each ion species, $\beta$ is the relative charge coefficient, which was used to quantify ion specificities in aggregation of colloidal minerals. According to the calculated results from Liu et al. ${ }^{11}$ the $\beta$ values for $\mathrm{K}^{+}$and $\mathrm{Na}^{+}$were 1.244 and 0.756 , and the $\beta$ values for $\mathrm{Mg}^{2+}$ and $\mathrm{Ca}^{2+}$ were 0.831 and 1.169 , respectively. $a^{0}(\mathrm{mmol} / \mathrm{L})$ represents the equilibrium concentration in bulk solution, $\tilde{c}(\mathrm{mmol} / \mathrm{L})$ is the ionic concentration in the diffuse layer, which can be calculated as,

$$
\tilde{c}=\frac{N \kappa}{S}
$$

with

$$
\kappa=\sqrt{\frac{8 \pi F^{2}\left(\frac{1}{2} \sum a^{0} Z^{2}\right)}{\varepsilon_{0} R T}}
$$

Where $\kappa(1 / \mathrm{dm})$ is the Debye-Huckel parameter, $N(\mathrm{~mol} / \mathrm{kg})$ is the surface charge number, $S\left(\mathrm{dm}^{2} / \mathrm{kg}\right)$ is the specific surface area, and $\varepsilon_{0}$ is the dielectric constant for water $\left(8.9 \times 10^{-10} \mathrm{C}^{2} / \mathrm{J} / \mathrm{dm}\right)$.

The potential $(\varphi(x), \mathrm{V})$ at the position of $x(\mathrm{~nm})$ can be calculated as: ${ }^{45}$

1:1 electrolyte solution:

$$
\varphi(x)=\frac{2 R T}{F} \ln \left(\frac{1-\lambda_{1: 1} e^{-\kappa x}}{1+\lambda_{1: 1} e^{-\kappa x}}\right)
$$

2:1 electrolyte solution:

$$
\varphi(x)=\frac{R T}{F} \ln \left[\frac{3}{2}\left(\frac{1-\lambda_{2: 1} e^{-k x}}{1+\lambda_{2: 1} e^{-k x}}\right)-\frac{1}{2}\right]
$$

where:

$$
\lambda_{1: 1}=\frac{1-\sqrt{e^{\frac{F \varphi_{0}}{R T}}}}{1+\sqrt{e^{\frac{F \varphi_{0}}{R T}}}} \lambda_{2: 1}=\frac{\sqrt{3}-\sqrt{2 e^{\frac{F \varphi_{0}}{R T}}+1}}{\sqrt{3}+\sqrt{2 e^{\frac{F \varphi_{0}}{R T}}+1}}
$$

After that, the electric field $E(x)(\mathrm{V} / \mathrm{m})$ around colloidal minerals can be calculated by Eq. (8): ${ }^{46}$

$$
E(x)=-\sqrt{\frac{2 R T}{\varepsilon_{0}}\left[a_{0}\left(e^{-\frac{Z F \varphi(x)}{R T}}-1\right)\right]}
$$

$2.3 \mathrm{~b}$ The electrostatic repulsive pressure: Based on the surface potential calculated from Eqs. (1) and (2), the potential at the mid-point of the two adjacent colloidal minerals $\left(\varphi_{(x / 2)}, \mathrm{V}\right)$ can also be calculated through Eq. (9): $:^{47,48}$

$$
\begin{array}{r}
\frac{\pi}{2}\left[1+\left(\frac{1}{2}\right)^{2} e^{\frac{2 Z F \phi_{(x / 2)}}{R T}}+\left(\frac{3}{8}\right)^{2} e^{\frac{4 Z F \phi_{(x / 2)}}{R T}}\right] \\
-\arcsin e^{\frac{Z F \phi_{0}-Z F \phi_{(x / 2)}}{2 R T}}=\frac{1}{4} d \kappa e^{\frac{-Z F \phi_{(x / 2)}}{2 R T}}
\end{array}
$$

Then, the electrostatic repulsive pressure $P_{\mathrm{EDL}}(x)$ (atm) between two adjacent colloidal minerals in a single 1:1 or 2:1 electrolyte solution can be calculated as: ${ }^{49}$

$$
P_{E D L}(\mathrm{x})=\frac{2}{101} R T a^{0}\left\{\cosh \left[\frac{Z F_{(x / 2)}}{R T}\right]-1\right\}
$$

\section{Results and Discussion}

\subsection{Hofmeister effects in aggregation of colloidal minerals}

The time-evolution effective hydrodynamic diameters of colloidal minerals have been measured in $\mathrm{NaNO}_{3}$, $\mathrm{KNO}_{3}, \mathrm{NH}_{4} \mathrm{NO}_{3}, \mathrm{Ca}\left(\mathrm{NO}_{3}\right)_{2}, \mathrm{Mg}\left(\mathrm{NO}_{3}\right)_{2}$ and $\mathrm{Cu}\left(\mathrm{NO}_{3}\right)_{2}$ solutions for various concentrations, see figure 1 . Then, the quantitative indicator for colloidal stability, critical coagulation concentration (CCC) values can be estimated as a function of the relationship between the total average aggregation (TAA) rates and electrolyte concentrations (figure 2 ) according to an approach proposed by Jia et al. ${ }^{50}$ The TAA rates $\left(\tilde{v}_{T}\left(f_{0}\right), \mathrm{nm} / \mathrm{min}\right)$ from $t=0$ to a given time ( $t=t_{0}=30$ minutes) during the aggregation processes can be calculated as follows:

$$
\tilde{v}_{T}\left(f_{0}\right)=\frac{1}{t_{0}} \int_{0}^{t_{0}} \frac{D(t)-D(0)}{t} d t
$$

where $f_{0}(\mathrm{mmol} / \mathrm{L})$ is the concentration of ion in the diffuse double layer, $D_{0}$ and $D(t)(\mathrm{nm})$ are the effective hydrodynamic diameters of mineral aggregates at the beginning and time $t_{0}$, respectively (see figure 1 ). 

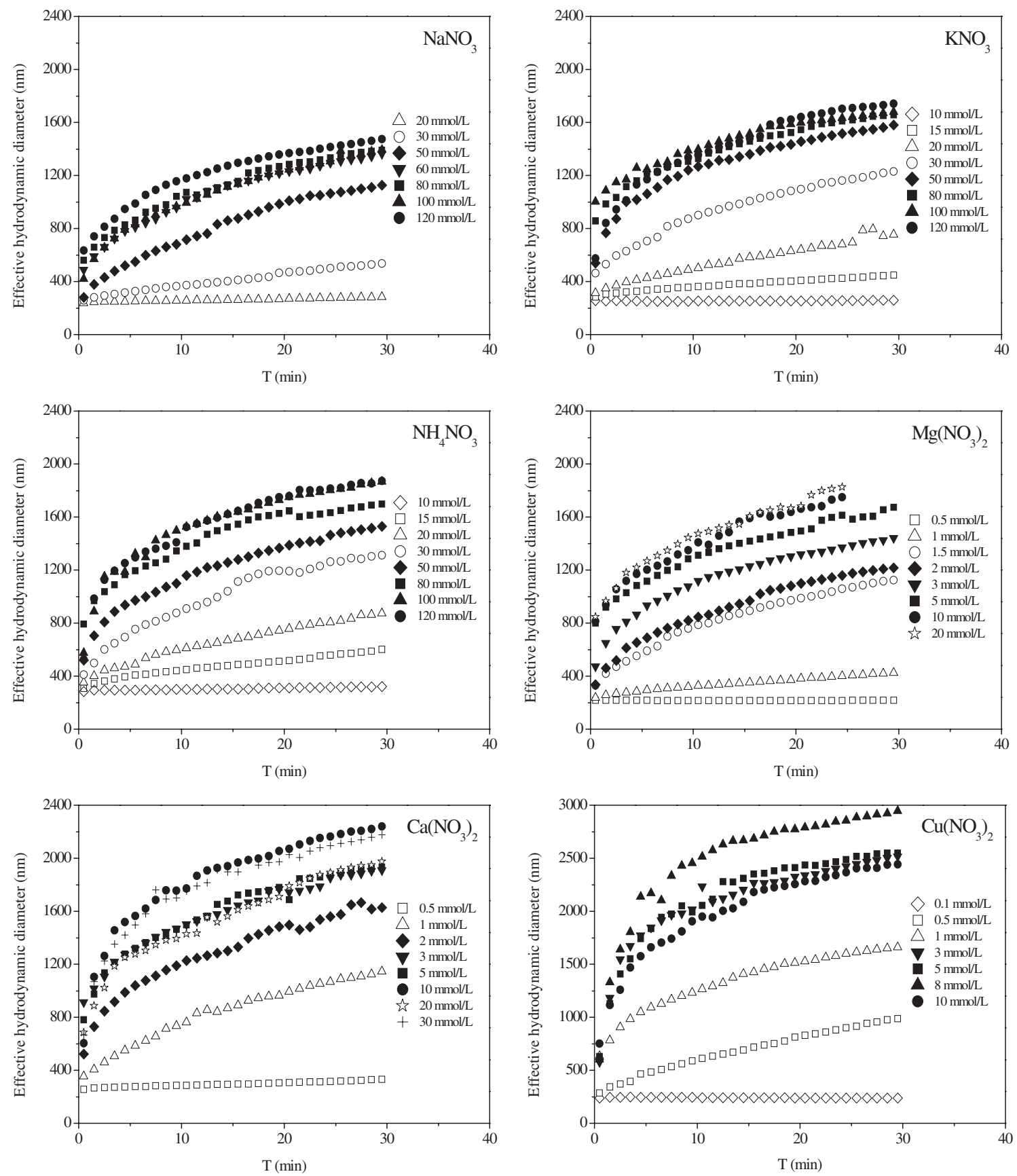

Figure 1. The time-evolution effective hydrodynamic diameter for the aggregates of colloidal minerals in electrolyte solutions for different concentrations.

The magnitudes of CCC values are inversely proportional to the capacity of different cation species in precipitating negatively charged colloidal minerals. According to the DLVO theory, cation species of identical valence would give rise to equivalent $\mathrm{CCC}$ values. However, different CCC values were detected due to Hofmeister effects, as displayed in figure 2. Obviously, the CCC values for $\mathrm{NaNO}_{3}, \mathrm{NH}_{4} \mathrm{NO}_{3}, \mathrm{KNO}_{3}$, $\mathrm{Mg}\left(\mathrm{NO}_{3}\right)_{2}, \mathrm{Ca}\left(\mathrm{NO}_{3}\right)_{2}$ and $\mathrm{Cu}\left(\mathrm{NO}_{3}\right)_{2}$ were $86.1,51.4$, $56.9,4.15,2.15$ and $1.72 \mathrm{mmol} / \mathrm{L}$, respectively, and the cation species were ordered as $\mathrm{Na}^{+}>\mathrm{K}^{+}>\mathrm{NH}_{4}^{+}$
$>>\mathrm{Mg}^{2+}>\mathrm{Ca}^{2+}>\mathrm{Cu}^{2+}$ for the $\mathrm{CCC}$ values. Therefore, Hofmeister series for aggregation of colloidal minerals were $\mathrm{Na}^{+}<\mathrm{K}^{+}<\mathrm{NH}_{4}^{+}<<\mathrm{Mg}^{2+}<\mathrm{Ca}^{2+}<\mathrm{Cu}^{2+}$ according to the relative effectiveness of various cation species to precipitate colloidal minerals. For monovalent cation species (figure 2a), the $\mathrm{CCC}$ of $\mathrm{Na}^{+}$was 1.5 times higher than that of $\mathrm{K}^{+}$, whereas the $\mathrm{CCC}$ value of $\mathrm{NH}_{4}^{+}$ was just a bit lower than that of $\mathrm{K}^{+}$. For divalent cation species (figure $2 \mathrm{~b}$ ), the $\mathrm{CCC}$ of $\mathrm{Mg}^{2+}$ was 2 and 2.5 times higher than that of $\mathrm{Ca}^{2+}$ and $\mathrm{Cu}^{2+}$, respectively. Clearly, Hofmeister effects of $\mathrm{Cu}^{2+}$ did not come from 


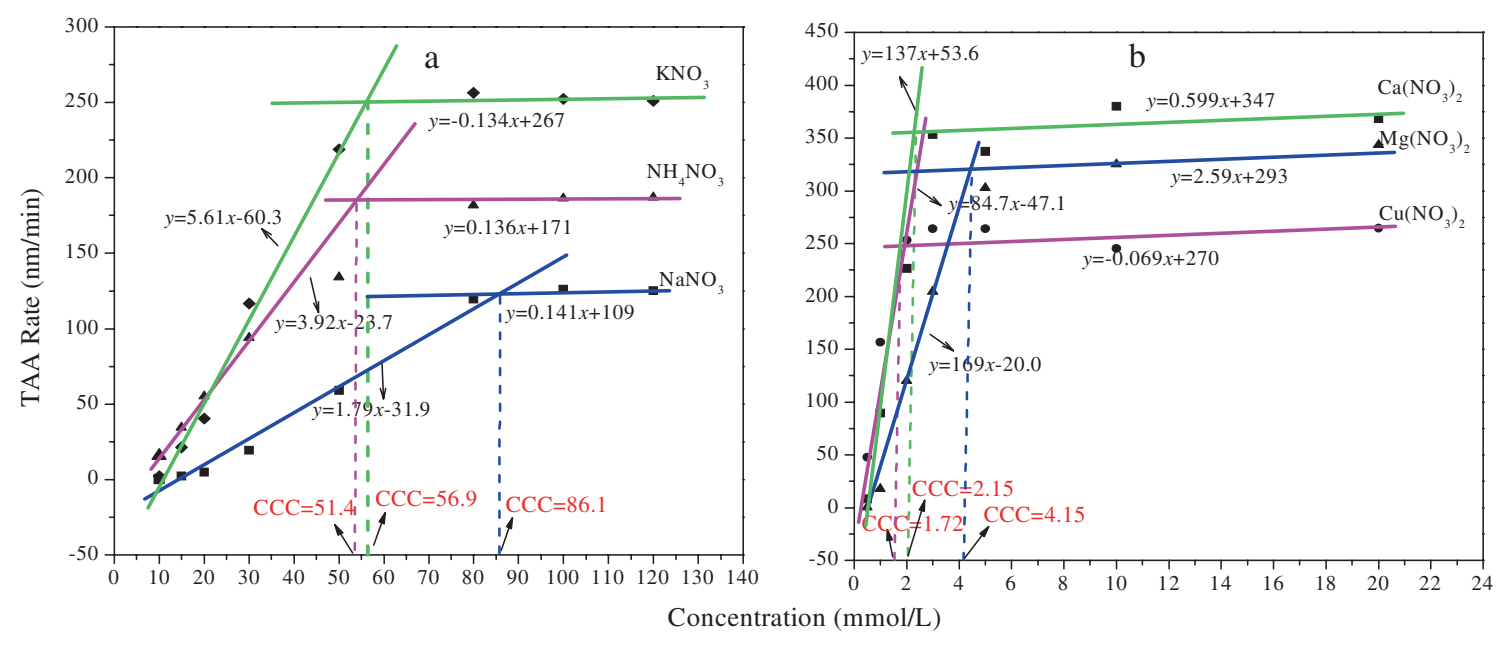

Figure 2. The TAA rates for the aggregates of colloidal minerals in, (a) 1:1 electrolyte solutions and, (b) 2:1 electrolyte solutions as a function of electrolyte concentrations. In the linear eq., $y$ is TAA rate and $x$ is electrolyte concentration.

the coordination adsorption of $\mathrm{Cu}^{2+}$ on colloidal mineral surface, because the coordinative adsorption on permanently charged colloidal mineral surface could be negligible. Divalent cation species were more efficient to precipitate negatively charged colloidal minerals than monovalent cation species due to extremely low CCC values in $\mathrm{Mg}^{2+}, \mathrm{Ca}^{2+}$, and $\mathrm{Cu}^{2+}$ solutions.

It was also apparent from figure 2 that there exist pronounced Hofmeister effects on TAA rates of aggregates at both low and high electrolyte concentrations. However, the relative position of cation species in Hofmeister series of TAA rates are dependent on electrolyte concentration. For monovalent cation species $\left(\mathrm{Na}^{+}, \mathrm{NH}_{4}^{+}\right.$and $\left.\mathrm{K}^{+}\right)$, the ranking of the TAA rates of aggregates was $\mathrm{NH}_{4}^{+}>\mathrm{K}^{+}>\mathrm{Na}^{+}$at electrolyte concentrations $<20 \mathrm{mmol} / \mathrm{L}$, while this sequence altered to $\mathrm{K}^{+}>\mathrm{NH}_{4}^{+}>\mathrm{Na}^{+}$when the electrolyte concentrations exceed $20 \mathrm{mmol} / \mathrm{L}$ (figure $2 \mathrm{a}$ ). Analogously, the sequence for divalent cation species $\left(\mathrm{Mg}^{2+}, \mathrm{Ca}^{2+}\right.$ and $\mathrm{Cu}^{2+}$ ) in TAA rates of aggregates followed $\mathrm{Cu}^{2+}>$ $\mathrm{Ca}^{2+}>\mathrm{Mg}^{2+}$ at relatively low electrolyte concentrations, and it changed to $\mathrm{Ca}^{2+}>\mathrm{Mg}^{2+}>\mathrm{Cu}^{2+}$ for cationic concentrations $>2 \mathrm{mmol} / \mathrm{L}$ (figure $2 \mathrm{~b}$ ). Obviously, $\mathrm{NH}_{4}^{+}$and $\mathrm{Cu}^{2+}$ inverted their positions as the cationic concentration increased.

\subsection{Conventional interpretation for Hofmeister effects}

The so called direct Hofmeister series referred to the relative efficiencies of ions in precipitating charged protein particles as a function of electrolyte concentration (e.g., $\left.\mathrm{NH}_{4}^{+}<\mathrm{K}^{+}<\mathrm{Na}^{+}<\mathrm{Ca}^{2+}<\mathrm{Mg}^{2+}\right)^{3,27,51}$ But reversed or altered ionic sequences have been observed in extensive systems when the sign of surface charge $e^{3,28,36,37}$ or hydrophobic/hydrophilic character of the surface s, $28,38^{2}$ was altered. In the current paper, although the negatively charged state and hydrophilicity of the colloidal minerals surface remained invariable during the aggregation process, partial Hofmeister series reversal was observed for both the CCC values and the TAA rates, implying that other surface properties of the colloidal minerals in aqueous solution should be taken into account to explain the observed Hofmeister effects.

On the other hand, Hofmeister effects were usually detected at high electrolyte concentrations $(>100$ $\mathrm{mmol} / \mathrm{L}$ ) in a host of experiments. ${ }^{37,38,52}$ Under relatively high electrolyte concentrations, the electrostatic effects were strongly screened, dispersion effects, ${ }^{23,24,30}$ ionic size and ionic hydration effects ${ }^{12,21,22}$ became significant which should account for the Hofmeister effects. However, pronounced Hofmeister effects were found at low electrolyte concentrations $(<100 \mathrm{mmol} / \mathrm{L})$ in our experiments (figure 2). Hofmeister effects at dilute concentrations are detected in a vast array of phenomena ranging from biological systems to colloidal systems. ${ }^{14,29,30,32}$ Ao et al. proposed cation specificity in interaction potential energies between polystyrene particles and glass slide at low cationic concentration, which was attributed to the effective size of the cation. ${ }^{32}$ Borah et al. pointed that Hofmeister effects in the adsorption of 2,4-dihydroxybenzoic acid onto $\alpha$ alumina were governed by the anionic size. ${ }^{29}$ However, Hofmeister effects in their researches increased with increasing electrolyte concentration, which are contradictory with the trends in the present work (figure 3 ). 


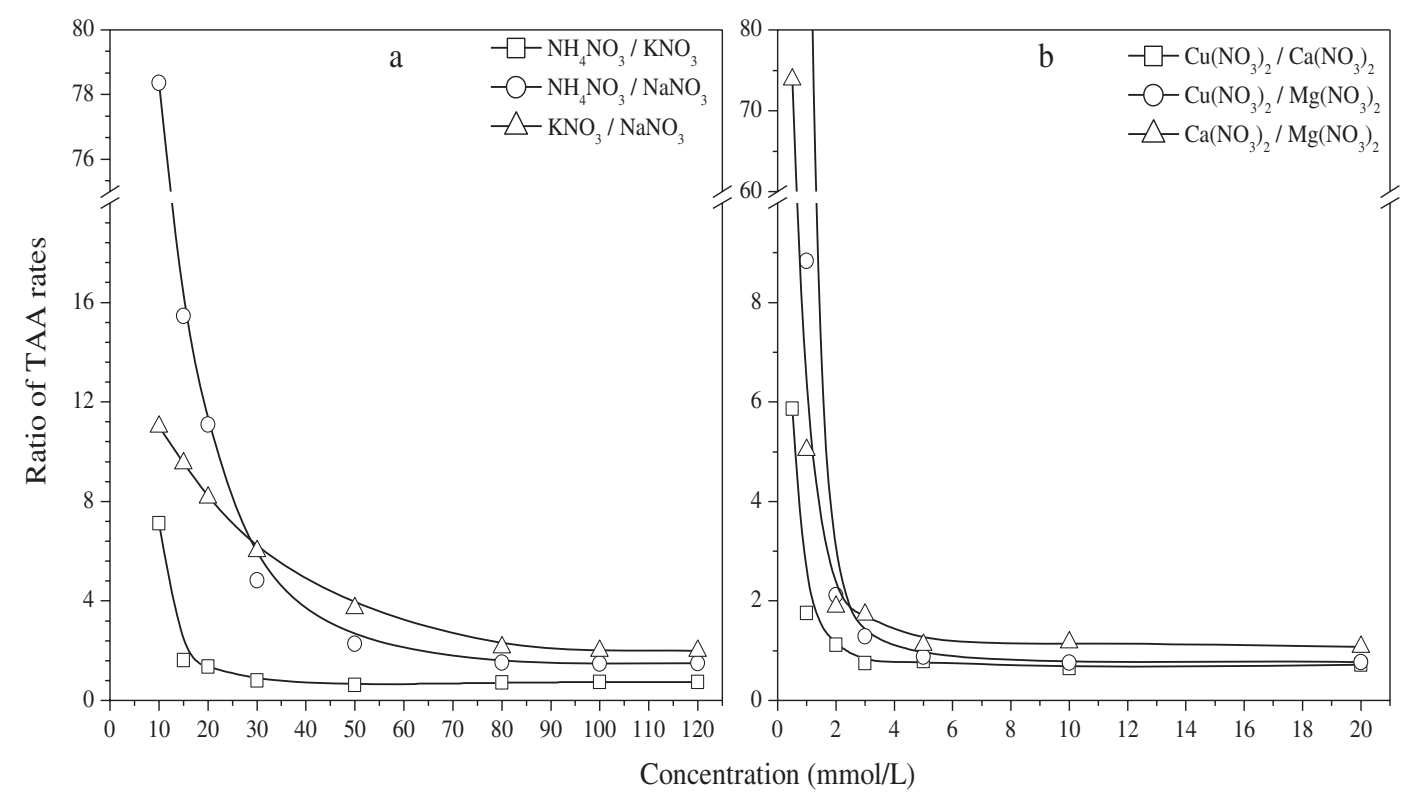

Figure 3. Ratios of the TAA rates for the aggregates of colloidal minerals in, (a) 1:1 electrolyte solutions and, (b) 2:1 electrolyte solutions as a function of electrolyte concentrations.

For example, As the concentration for 1:1 electrolyte solutions $\left(\mathrm{NH}_{4} \mathrm{NO}_{3}, \mathrm{KNO}_{3}\right.$, and $\left.\mathrm{NaNO}_{3}\right)$ increased from 10 to $20 \mathrm{mmol} / \mathrm{L}$, the value of $\tilde{v}\left(\mathrm{NH}_{4}^{+}\right) / \tilde{v}\left(\mathrm{~K}^{+}\right)$, $\tilde{v}\left(\mathrm{NH}_{4}^{+}\right) / \tilde{v}\left(\mathrm{Na}^{+}\right)$and $\tilde{v}\left(\mathrm{~K}^{+}\right) / \tilde{v}\left(\mathrm{Na}^{+}\right)$decreased sharply from 7.11 to $1.36,78.4$ to 11.1 and 11.0 to 8.15 , respectively (figure 3a). Similarly, along with the concentration for 2:1 electrolyte solutions $\left(\mathrm{Cu}\left(\mathrm{NO}_{3}\right)_{2}, \mathrm{Mg}\left(\mathrm{NO}_{3}\right)_{2}\right.$ and $\left.\mathrm{Ca}\left(\mathrm{NO}_{3}\right)_{2}\right)$ increased from 1 to $2 \mathrm{mmol} / \mathrm{L}$, the value of $\tilde{v}\left(\mathrm{Cu}^{2+}\right) / \tilde{v}\left(\mathrm{Mg}^{2+}\right), \tilde{v}\left(\mathrm{Cu}^{2+}\right) / \tilde{v}\left(\mathrm{Ca}^{2+}\right)$ and $\tilde{v}\left(\mathrm{Ca}^{2+}\right) / \tilde{v}\left(\mathrm{Mg}^{2+}\right)$ declined sharply from 433 to 2.11, 5.86 to 1.12 and 73.9 to 1.89 , respectively (figure $3 b$ ).

In the light of both ions and intervening charged colloidal minerals interfaces are hydrated in bulk solution, the following discussion will clarify the impact of hydration effects on Hofmeister effects. According to the classical "like dissolves like" rule, there seems to be a greater probability for more hydrated cation species (e.g., $\mathrm{Na}^{+}$rather than $\mathrm{K}^{+}, \mathrm{Mg}^{2+}$ rather than $\mathrm{Ca}^{2+}$ ) to approach closely the hydrated colloidal minerals surfaces. The hydrated layers of the cations and colloidal mineral surfaces may overlap, resulting in the center of the cations moving further close to the edge of the hydration layers of the particle surfaces. ${ }^{33}$ Accordingly, strongly hydrated cation species, $\mathrm{Na}^{+}$and $\mathrm{Mg}^{2+}$ should penetrate more easily into the inner hydration layer of the particle, resulting in more effective screening of the electric field arising from the abundant surface charges. Thus, colloidal minerals are more likely to aggregate in $\mathrm{Na}^{+}$and $\mathrm{Mg}^{2+}$ solutions than $\mathrm{K}^{+}$and $\mathrm{Ca}^{2+}$ solutions at a given ionic concentration, respectively, which is inconsistent with the experimental observation (figures 2 and 3). To conclude, none of the above classical theories (dispersion effects, ionic size and hydration effects) can give a reasonable interpretation for the observed Hofmeister effects. However, several recent investigations on the interactions between inorganic colloidal nanocrystals or nanocrystal solids with size less than $10 \mathrm{~nm}$ (semiconductor, metals and metal oxides, etc.) in the presence of nitrate or other cation/anion solutions had suggested that DLVO becomes inadequate and the specific binding of ions to nanocrystal surface, which depend on the chemical nature of nanocrystal surface and ions, can play a dominant role. ${ }^{19,20,53}$ This implies that properties of colloidal surface and cations are equally important in the aggregation of colloidal minerals. Furthermore, similar Hofmeister effects in charged particle interactions were also found by Liu et al. ${ }^{34}$ and Tian et al. ${ }^{33} \mathrm{In}$ their work, ionic polarization in strong electric field was regarded as the origin of Hofmeister effects in ion-surface interactions. But the experimental materials in their work were merely pure minerals (i.e., illite and montmorillonite), which are the dominant components of the colloidal minerals in our work, implying that ionic polarization and electric field arising from the charged colloidal minerals may also be an important contributor to Hofmeister effects in our study.

\subsection{Impact of electric field on Hofmeister effects in ag- gregation of colloidal minerals}

Note that the surface of colloidal minerals establish a strong electric field of $-3.41 \times 10^{8} \mathrm{~V} / \mathrm{m}$ in suspension. 
At an arbitrary distance from the colloidal mineral surface (e.g., $1.5 \mathrm{~nm}$ ), the electric field strength is much stronger at relatively lower electrolyte concentrations for both 1:1 and 2:1 electrolyte solutions (figure 4). Cations are strongly polarized in such a strong electric field ${ }^{54,55}$ and the increment of cationic polarizabilities are relevant to the electron configuration of cations, which vary remarkably for different cation species. The cation species with larger main and angular quantum numbers have "softer" electron cloud which then exhibit much stronger quantum fluctuation, resulting in a stronger polarization effect when interacting with the negatively charged particle surface. ${ }^{33}$ The higher the polarizability of cations, higher is the propensity for the particle surface, ${ }^{14,30}$ indicating that these cation species can be more effective to precipitate the colloidal minerals, and this is the production of Hofmeister effects in aggregation of colloidal minerals.

In our experiments, for monovalent cation species, $\mathrm{NH}_{4}^{+}$has the softest electron cloud due to its largest ionic radius $(0.143 \mathrm{~nm}),{ }^{56}$ highest static polarizability of $1.86 \AA^{3} .^{3,15}$ and most complex electron conformation in tetrahedral geometry. As a result, $\mathrm{NH}_{4}^{+}$ is the easiest to be polarized in strong electric field with respect to other monovalent cation species at the same concentration. The ionic radius of $\mathrm{K}^{+}(0.133$ $\mathrm{nm})$ is larger than that of $\mathrm{Na}^{+}(0.098 \mathrm{~nm})$, and the number of extranuclear electron shell for $\mathrm{K}^{+}$surpassed that for $\mathrm{Na}^{+}$(table 1), the static polarizability of $\mathrm{K}^{+}\left(0.814 \AA^{3}\right)$ is also higher than that of $\mathrm{Na}^{+}\left(0.139 \AA^{3}\right),{ }^{57}$ which implied that $\mathrm{K}^{+}$rather than $\mathrm{Na}^{+}$is more efficient to precipitate charged colloidal minerals. These are inconsistent with the Hofmeister series of $\mathrm{CCC}$ values $\left(\mathrm{NH}_{4}^{+}<\mathrm{K}^{+}<\mathrm{Na}^{+}\right)$. Analogously, for divalent cation species, although the ionic radius increased as $\mathrm{Ca}^{2+}(0.094 \mathrm{~nm})>\mathrm{Cu}^{2+}(0.077 \mathrm{~nm})>$ $\mathrm{Mg}^{2+}(0.065 \mathrm{~nm}),{ }^{56}$ only $\mathrm{Cu}^{2+}$ has the "d" orbital that is far from the nucleus, and the extranuclear electron cloud of $\mathrm{Cu}^{2+}$ was the softest, as a result, $\mathrm{Cu}^{2+}$ would be the easiest to be polarized in strong electric field as compared with $\mathrm{Ca}^{2+}$ and $\mathrm{Mg}^{2+}$ (table 1). $\mathrm{Ca}^{2+}$ is easier to screen the electric field in diffuse layer and, therefore, more efficient to precipitate colloidal minerals than $\mathrm{Mg}^{2+}$ due to the fact that it has a larger ionic radius and higher static palarizibility $\left(0.469 \AA^{3}\right){ }^{16}$ These could also fully explain the Hofmeister series of CCC values $\left(\mathrm{Mg}^{2+}>\mathrm{Ca}^{2+}>\mathrm{Cu}^{2+}\right)$ (figure 2).

Moreover, with the increase of electrolyte concentration, $\mathrm{NH}_{4}^{+}$and $\mathrm{Cu}^{2+}$ which have stronger polarization effect than other cation species with identical valence were found to alter their positions within the Hofmeister series of TAA rates (figure 2), suggesting that Hofmeister effects might be influenced by the strength of the

Table 1. The physical characteristics for different cation species.

\begin{tabular}{lccc}
\hline Cation & $\begin{array}{c}\text { ionic } \\
\text { radius } \\
(\mathrm{nm})\end{array}$ & $\begin{array}{c}\text { Extranuclear electron } \\
\text { arrangement of } \\
\text { the cation }\end{array}$ & $\begin{array}{c}\text { Static } \\
\text { polarizability } \\
\left(\AA^{3}\right)\end{array}$ \\
\hline $\mathrm{Na}^{+}$ & $0.098^{\mathrm{a}}$ & $1 \mathrm{~s}^{2} 2 \mathrm{~s}^{2} 2 \mathrm{p}^{6}$ & $0.139^{\mathrm{b}}$ \\
$\mathrm{K}^{+}$ & $0.133^{\mathrm{a}}$ & $1 \mathrm{~s}^{2} 2 \mathrm{~s}^{2} 2 \mathrm{p}^{6} 3 \mathrm{~s}^{2} 3 \mathrm{p}^{6}$ & $0.814^{\mathrm{b}}$ \\
$\mathrm{NH}_{4}^{+}$ & $0.143^{\mathrm{a}}$ & Tetrahedral hybridization & $1.86^{\mathrm{cd}}$ \\
$\mathrm{Mg}^{2+}$ & $0.065^{\mathrm{a}}$ & $1 \mathrm{~s}^{2} 2 \mathrm{~s}^{2} 2 \mathrm{p}^{6}$ & $0.0704^{\mathrm{b}}$ \\
$\mathrm{Ca}^{2+}$ & $0.094^{\mathrm{a}}$ & $1 \mathrm{~s}^{2} 2 \mathrm{~s}^{2} 2 \mathrm{p}^{6} 3 \mathrm{~s}^{2} 3 \mathrm{p}^{6}$ & $0.469^{\mathrm{b}}$ \\
$\mathrm{Cu}^{2+}$ & $0.077^{\mathrm{a}}$ & $1 \mathrm{~s}^{2} 2 \mathrm{~s}^{2} 2 \mathrm{p}^{6} 3 \mathrm{~s}^{2} 3 \mathrm{p}^{6} 3 \mathrm{~d}^{9}$ & - \\
\hline
\end{tabular}

${ }^{\mathrm{a} C o n w a y}$ and Conway, ${ }^{56}{ }^{\mathrm{b}}$ Parsons and Ninham, ${ }^{16}{ }^{\mathrm{c}} \mathrm{Kunz}$ et al. ${ }^{15 \mathrm{~d}}$ López-Léon et al. ${ }^{3}$

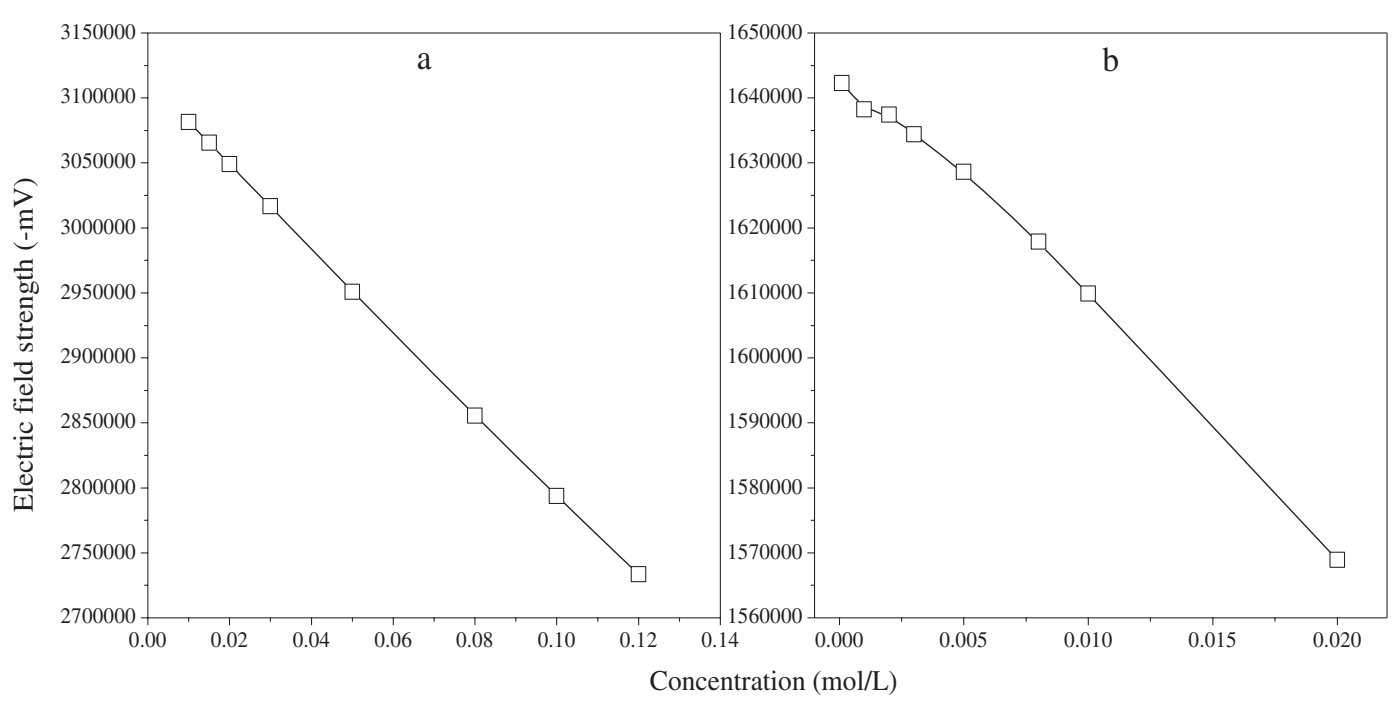

Figure 4. Electric field strength under, (a) 1:1 electrolyte solutions and, (b) 2:1 electrolyte solution $\mathrm{s}$ as a function of electrolyte concentration. 
electric field around colloidal minerals. This hypothesis is also supported by the variation tendency that Hofmeister effects became more noticeable with the decreasing electrolyte concentration or increasing electric field strength (figure 3), indicating that the differences of polarization effect among cation species could be enhanced by the strong external electric field. ${ }^{34}$ Stronger the electric field strength, more remarkable might be the enhancement effects, resulting in more noticeable differences in screening the high external electric field as well as the corresponding electrostatic repulsive interaction between the colloidal minerals, which further facilitate the more remarkable Hofmeister effects in aggregation of colloidal minerals. Subsequently, $\mathrm{K}^{+}, \mathrm{Na}^{+}, \mathrm{Mg}^{2+}$ and $\mathrm{Ca}^{2+}$ are taken as examples to quantitatively disclose the impact of electric field on Hofmeister effects in aggregation of colloidal minerals.

After introducing the relative charge coefficient $\beta$, which took the strong polarization of different cation species into account, in the Eqs. (1) to (8), the electric field strength at $1.5 \mathrm{~nm}$ from the colloidal surface under electrolyte solutions with different cation species are calculated. Then the differences in the electric field strength between two monovalent cation species and two divalent cation species under different electrolyte concentrations are shown in figure 5. Obviously, the absolute values of differences of electric field strength between $\mathrm{K}^{+}$and $\mathrm{Na}^{+}$increased rapidly from 370000 to $500000 \mathrm{~V} / \mathrm{m}$ as the electrolyte concentration decreased from 120 to $10 \mathrm{mmol} / \mathrm{L}$. Analogously, the absolute values of differences in the electric field strength between $\mathrm{Mg}^{2+}$ and $\mathrm{Ca}^{2+}$ increased from 57500 to $82500 \mathrm{~V} / \mathrm{m}$ as the electrolyte concentration decreased from 20 to $1 \mathrm{mmol} / \mathrm{L}$. Moreover, at a given electrolyte concentration (e.g., $10 \mathrm{mmol} / \mathrm{L}$ ), the difference in electric field between monovalent cation species was one order of magnitude larger than that between divalent cation species, because divalent cations are more efficient in screening electric fieldstrength around particle surface.

The particle aggregation is actually determined by the competition between the attractive van der Waals force and repulsive electrostatic force, where the later is dependent on the electric field strength in the diffuse layer. Then, we will calculate electrostatic repulsive interaction between adjacent colloidal minerals under solutions with various cation species by Eqs. (9) and (10) in the succeeding discussion, in order to give a direct proof for aggregation of colloidal minerals. The relationship between differences of electrostatic repulsive pressure and differences of electric field between two cation species with identical valence are displayed in figure 6.

Figure 6 illustrates that, for two cation species with equivalent valence, the differences in electrostatic repulsive pressure are positively proportional to the differences of electric field strength. As the absolute value of differences of electric field strength between $\mathrm{K}^{+}$and $\mathrm{Na}^{+}$rapidly increased from 370000 to $500000 \mathrm{~V} / \mathrm{m}$, the differences of electrostatic repulsive pressure between $\mathrm{K}^{+}$and $\mathrm{Na}^{+}$increased from 11 to 16 atm. Similarly, as the absolute value of differences of electric field strength between $\mathrm{Mg}^{2+}$ and $\mathrm{Ca}^{2+}$ increased from 57500 to $82500 \mathrm{~V} / \mathrm{m}$, the differences of electrostatic repulsive pressure between $\mathrm{Mg}^{2+}$ and $\mathrm{Ca}^{2+}$ gradually increased

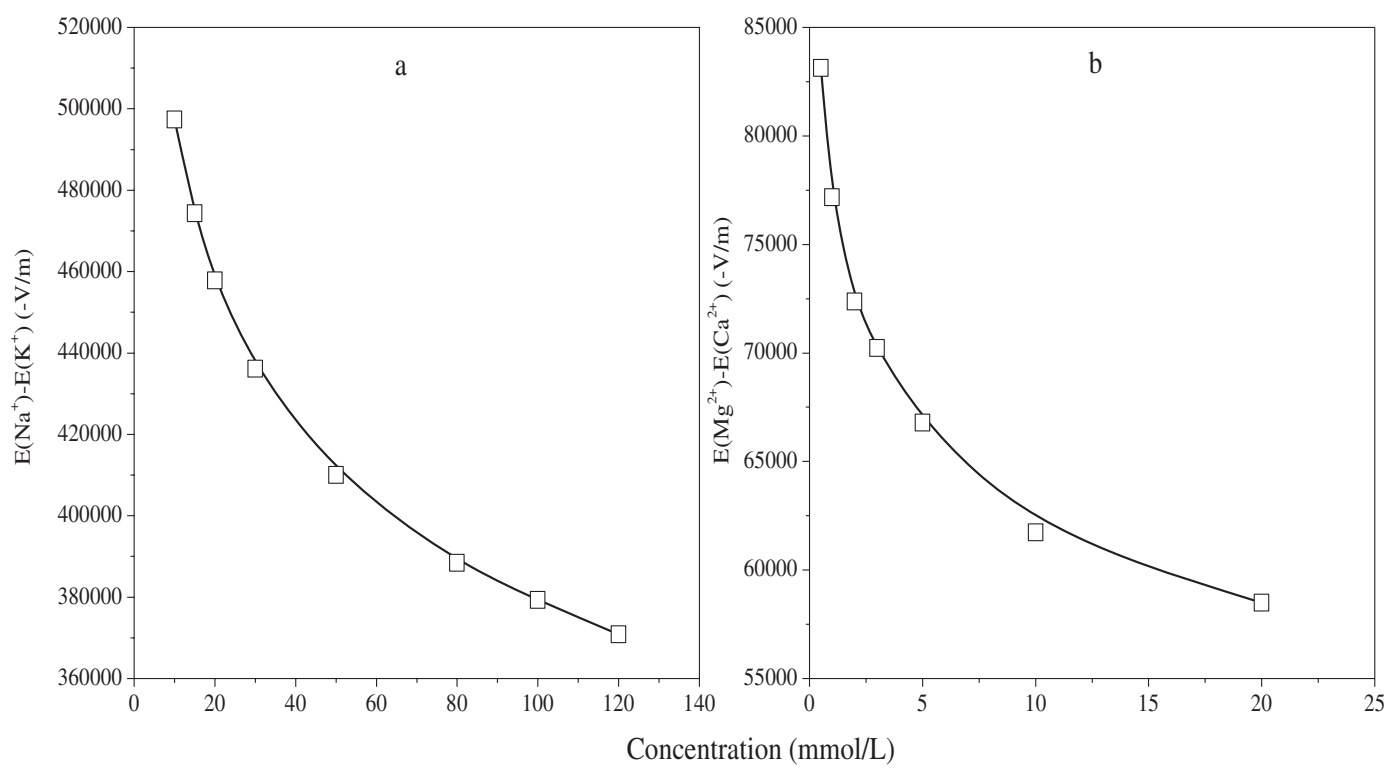

Figure 5. Differences of electric field strength for the aggregates of colloidal minerals in, (a) $\mathrm{Na}^{+}$ and $\mathrm{K}^{+}$solutions and, (b) $\mathrm{Ca}^{2+}$ and $\mathrm{Mg}^{2+}$ solutions as a function of ionic concentrations. 
from $1.2 \mathrm{~atm}$ to $1.8 \mathrm{~atm}$. The differences of electrostatic repulsive pressure between $\mathrm{K}^{+}$and $\mathrm{Na}^{+}, \mathrm{Mg}^{2+}$ and $\mathrm{Ca}^{2+}$ can facilitate the differences of interactions between colloidal minerals, which will influence their aggregation characteristics. Therefore, the TAA rates of aggregates in the presence of these cation species diverged notably as shown in figure 7 .

It is obvious from figure 7 that Hofmeister effects of TAA rates increased exponentially with the increase in differences of electrostatic repulsive pressure, the correlation coefficient between the two parameters exceed
0.85. As the differences of electrostatic repulsive pressure between $\mathrm{K}^{+}$and $\mathrm{Na}^{+}$increased from 11 to $16 \mathrm{~atm}$, the ratio of their TAA rates rapidly increased from 2 to 12. Accordingly, as the differences of electrostatic repulsive pressure between $\mathrm{Mg}^{2+}$ and $\mathrm{Ca}^{2+}$ increased from 1.2 to $1.8 \mathrm{~atm}$, the ratio of TAA rates for these two cation species increased from 1 to 5 . These results indicated that, with the variation of electrolyte concentration, the differences of electrostatic repulsive pressure resulting from the differences of electric field strength among different cation species can fully explain the
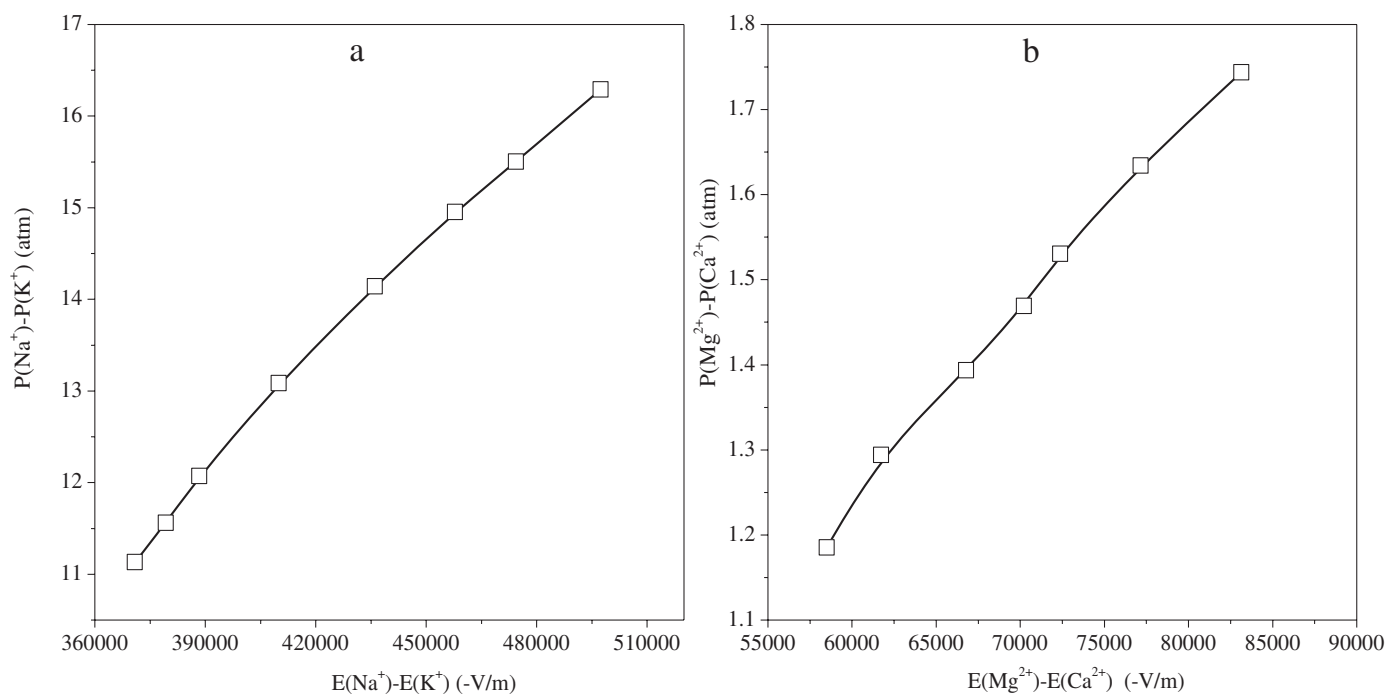

Figure 6. Differences of electrostatic repulsive pressure for the aggregates of colloidal minerals in, (a) $\mathrm{Na}^{+}$and $\mathrm{K}^{+}$solutions and, (b) $\mathrm{Ca}^{2+}$ and $\mathrm{Mg}^{2+}$ solutions as a function of the differences of electric field strength.
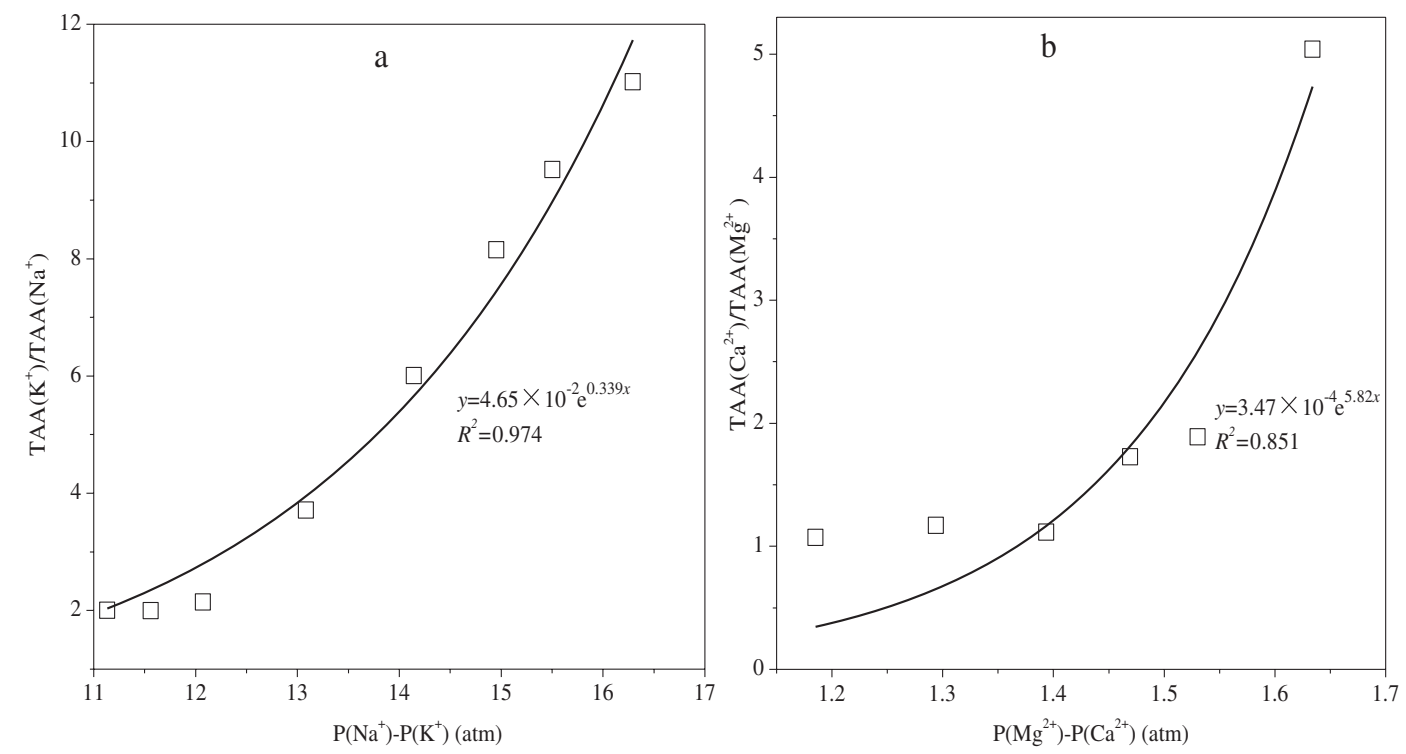

Figure 7. Ratios of the TAA rates for the aggregates of colloidal minerals in, (a) $\mathrm{Na}^{+}$and $\mathrm{K}^{+}$ solutions and, (b) $\mathrm{Ca}^{2+}$ and $\mathrm{Mg}^{2+}$ solutions as a function of the differences of electrostatic repulsive pressure. In the equation, $y$ is Ratio of the TAA rates and $x$ is the difference of electric repulsive pressure. 
impact of external electric field on Hofmeister effects in aggregation of colloidal minerals. Specially, the magnitude of electric field around colloidal minerals might influence the polarization effect of different cation species, which further influence the distribution of these cation species in the diffuse layer, which should induce differences of electric field and electrostatic repulsive pressure between colloidal minerals, and result in pronounced Hofmeister effects in aggregation of colloidal minerals.

\section{Conclusions}

Hofmeister effects are observed in innumerous systems under both low and high electrolyte concentrations, but a clear description of these effects in interaction of multi-component colloidal minerals is still lacking. In this study, we found pronounced Hofmeister effects in aggregation of colloidal minerals. Strong electric field near colloidal minerals surface as well as the polarization of adsorbed ions in the field should account for the Hofmeister effects. Our results can give a reference for other systems with non-ideal, non-linear, multi-body interactions.

The CCC values and TAA rates of aggregates have been used to quantitatively characterize Hofmeister effects in aggregation of the colloidal minerals under low electrolyte concentrations $(<100 \mathrm{mmol} / \mathrm{L})$. The Hofmeister series followed $\mathrm{Na}^{+}(86.1 \mathrm{mmol} / \mathrm{L})>$ $\mathrm{K}^{+}(56.9 \mathrm{mmol} / \mathrm{L})>\mathrm{NH}_{4}^{+}(51.4 \mathrm{mmol} / \mathrm{L})>\mathrm{Mg}^{2+}(4.15$ $\mathrm{mmol} / \mathrm{L})>\mathrm{Ca}^{2+}(2.15 \mathrm{mmol} / \mathrm{L})>\mathrm{Cu}^{2+}(1.72 \mathrm{mmol} / \mathrm{L})$ for CCC values, indicating that softer the electron cloud of cation species, easier that the cation species would be polarized, and stronger would be the Hofmeister effects. Hofmeister effects for TAA rates increased exponentially with the decrease of electrolyte concentration and these results cannot be explained by the classical theories including ionic size, hydration and dispersion forces, since the most important factor, strong electric field arising from surface charges of colloidal minerals, was neglected. When the relative charge coefficients $\beta$ resulting from the polarization of cation species and strong electric field are included, the observed Hofmeister effects could be qualitatively explained.

\section{Acknowledgements}

This work was supported by the National Natural Science Foundation of China (Grant No. 40971146 and 41501241), the Chongqing Research Program of Basic Research and Frontier Technology (No. cstc2014jcyjA00034 and cstc2015jcyjA00036) and China Postdoctoral Science Foundation (Grant No. 2015M572430).

\section{References}

1. Tian R, Yang G, Zhu C, Liu X M and Li H 2015 J. Phys. Chem. C 1194856

2. Tian R, Yang G, Liu X M, Huang C, Gao X D and Li H 2015 J. Chem. Sci. 1271083

3. López-León T, Santander-Ortega M J, Ortega-Vinuesa J L and Bastos-González D 2008 J. Phys. Chem. C 112 16060

4. Kunz W 2010 In Specific Ion Effects (Singapore: World Scientific)

5. Lo Nostro P, Ninham B W, Lo Nostro A, Pesavento G, Fratoni L and Baglioni P 2005 Phys. Biol. 21

6. Lo Nostro P, Ninham B W, Milani S, Lo Nostro A, Pesavento G and Baglioni P 2006 Biophys. Chem. 124 208

7. Zhang Y, Furyk S, Bergbreiter D E and Cremer P 2005 J. Am. Chem. Soc. 12714505

8. Salis A, Bilanicova D, Ninham B W and Monduzzi M 2007 J. Phys. Chem. B 1111149

9. Bilaničová D, Salis A, Ninham B W and Monduzzi M 2008 J. Phys. Chem. B 11212066

10. Nostro P L, Nostro A L, Ninham B W, Pesavento G, Fratoni L and Baglioni P 2004 Curr. Opin. Colloid Interf. Sci. 997

11. Liu X M, Li H, Du W, Tian R, Li R and Jiang X J 2013 J. Phys. Chem. C 1176245

12. Ruiz-Agudo E, Urosevic M, Putnis C V, RodríguezNavarro C, Cardell C and Putnis A 2011 Chem. Geol. 281364

13. Conway B and Ayranci E 1999 J. Solution Chem. 28163

14. Das M R, Borah J M, Kunz W, Ninham B W and Mahiuddin S 2010 J. Colloid Interf. Sci. 344482

15. Kunz W, Belloni L, Bernard O and Ninham B W 2004 J. Phys. Chem. B 1082398

16. Parsons D F and Ninham B W 2010 Langmuir 266430

17. Hosoda H, Mori H, Sogoshi N, Nagasawa A and Nakabayashi S 2004 J.Phys. Chem. A 1081461

18. Zavitsas A A 2001 J. Phys. Chem. B 1057805

19. Nag A, Chung D S, Dolzhnikov D S, Dimitrijevic N M, Chattopadhyay S, Shibata T and Talapin D V 2012 J. Am. Chem. Soc. 13413604

20. Kadlag K P, Rao M J and Nag A 2013 J. Phys. Chem. Lett. 41676

21. Manciu M and Ruckenstein E 2003 Adv. Colloid Interface Sci. $\mathbf{1 0 5} 63$

22. Kathmann S M, Schenter G K and Garrett B C 2005 Phys. Rev. Lett. 94116104

23. Martín-Molina A, Ibarra-Armenta J G and QuesadaPérez M 2009 J. Phys. Chem. B 1132414

24. Deniz V, Boström M, Bratko D, Tavares F and Ninham B 2008 Colloids Surf. A 31998

25. Bostrom M, Craig V, Albion R, Williams D and Ninham B 2003 J. Phys. Chem. B 1072875

26. Bostrom M, Williams D and Ninham B 2002 J. Phys Chem. B 1067908

27. Parsons D F, Boström M, Nostro P L and Ninham B W 2011 Phys. Chem. Chem. Phys. 1312352

28. Calero C, Faraudo J and Bastos-González D $2011 \mathrm{~J}$. Am. Chem. Soc. 13315025

29. Borah J M, Mahiuddin S, Sarma N, Parsons D F and Ninham B W 2011 Langmuir 278710 
30. Bostrom M, Lima E, Tavares F and Ninham B $2008 \mathrm{~J}$. Chem. Phys. 128135104

31. Kim H K, Tuite E, Nordén B and Ninham B W 2001 Euro. Phys. J. E 4411

32. Ao Z, Liu G and Zhang G 2011 J. Phys. Chem. C 115 2284

33. Tian R, Yang G, Li H, Gao X, Liu X M, Zhu H L and Tang Y 2014 Phys. Chem. Chem. Phys. 168828

34. Liu X M, Li H, Li R, Xie D T, Ni J P and Wu L 2014 Sci. Rep. 4

35. Tian R, Yang G, Tang Y, Liu X M, Li R, Zhu H and Li H 2015 PLoS One 101

36. Schwierz N, Horinek D and Netz R R 2010 Langmuir 267370

37. Dishon M, Zohar O and Sivan U 2009 Langmuir 25 2831

38. Schwierz N, Horinek D and Netz R R 2013 Langmuir 292602

39. Li H, Hou J, Liu X M, Li R, Zhu H and Wu L 2011 Soil Sci. Soc. Am. J. 752128

40. Kinraide T B and Wang P 2010 J. Exp. Bot. 612507

41. Boroudjerdi H, Kim Y W, Naji A, Netz R, Schlagberger $\mathrm{X}$ and Serr A 2005 Phys.Rep. 416129

42. Liu X M, Li H, Li R, Tian R and Xu C Y 2013 Analyst 1381122

43. Xiong Y, Chen J and Zhang J 1985 In Soil Colloid (2): Methods for soil colloid research (In Chinese). (Beijing: Science Press) p.10
44. Staunton S and Quiquampoix H 1994 J. Colloid Interf. Sci. 16689

45. Liu X M, Li H, Li R and Tian R 2013 Surf. Sci. 607197

46. Li S, Li H, Xu C Y, Huang X R, Xie D T and Ni J P 2013 Soil Sci. Soc. Am. J. 771563

47. Li H, Peng X H, Wu L S, Jia M Y and Zhu H L $2009 \mathrm{~J}$. Phys. Chem. C 11344

48. Hou J, Li H, Zhu H L and Wu L S 2009 Soil Sci. Soc. Am. J. 731658

49. Ducker W A, Senden T J and Pashley R M 1992 Langmuir 81831

50. Jia M Y, Zhu H L, Tian R and Gao X D 2013 J. Soils Sediments 13325

51. Kunz W, Henle J and Ninham B W 2004 Curr. Opin. Colloid Interface Sci. 919

52. Kosmulski M 2002 Langmuir 18785

53. Rosen E L, Buonsanti R, Llordes A, Sawvel A M, Milliron D J and Helms B A 2012 Angew. Chem. Int. Ed. 51684

54. Stellwagen E and Stellwagen N C 2003 Biophys. J. 84 1855

55. Vrbka L, Mucha M, Minofar B, Jungwirth P, Brown E C and Tobias D J 2004 Curr. Opin. Colloid Interface Sci. 967

56. Conway B E 1981 In Ionic Hydration in Chemistry and Biophysics (New York: Elsevier)

57. Parsons D F and Ninham B W 2009 Langmuir 26 1816 